\title{
REPORT
}

\section{Proceedings of the 1998 Tri-Service Symposium on Occupational Medicine}

\author{
Maj MCM Bricknell \\ MB, MMedSci, MFOM, MRCGP, DRCOG, DFFP, RAMC
}

Army Medical Directorate, Keogh Barracks, Ash Vale, Aldershot, Hants GU12 5RR

Col CG Batty

MBE, MB, ChB, MSc, FRCS(Ed), MFOM, late RAMC

Army Professor of Occupational Medicine

Headquarters 4th Division, Steeles Road, Aldershot, Hants GU11 2DP

\author{
Surg Cdr AW Murrison \\ MD, DPH, MFOM, RN \\ Principal Medical Officer
}

HM Naval Base, Portsmouth, Hants POI 3ND

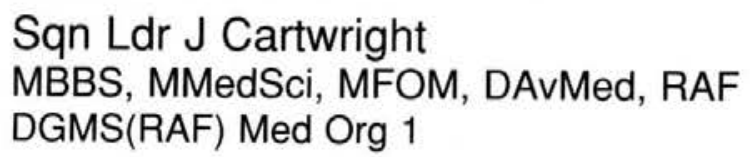

\section{Headquarters Personnel and Training Command, RAF Innsworth, Gloucester GL3 IEZ}

The Proceedings of the 1998 Tri-Service Symposium in Occupational Medicine held over 2-3 September 1998 are reported. The Symposium was held at the Institute of Naval Medicine by kind permission of the Medical Officer In Charge, Surgeon Commodore McMillan. Sixty five delegates attended what was probably the largest single gathering of Occupational Physicians from the Defence Medical Services ever assembled. One of the principle benefits of the symposium was the opportunity to share ideas and experiences of occupational medicine across the complete Service environment. This report publishes abstracts of the papers presented at the Symposium.

The day started with a tour of the Institute of Naval Medicine. This provided an opportunity for delegates to see the extensive research facilities available in support of the Royal Navy. This was reinforced by a comprehensive briefing by Surgeon Commodore McMillan on the roles and capabilities of the INM.

The meeting was formally opened with a presentation by the Defence Medical Postgraduate Dean, Surgeon Commodore IL Jenkins, on the organisation of postgraduate training in Occupational Medicine in the Defence Medical Services. The differences between Specialist Registrars in Occupational Medicine training and other clinical specialities were highlighted. The organisation of occupational medicine programmes and the role of Postgraduate Deans were reviewed. Finally problems associated with delays in submission of dissertations and interruptions in higher professional training were discussed.

\section{The Thirty Years War: Quality Assured Practice - Dr CC Harling.}

The enigmatically titled keynote speech was given by the President of the Faculty of Occupational Medicine. Dr Harling identified that 1998 will be seen as a watershed in medical practice with the development of mechanisms for prospective quality assurance of medical practice. This is in contrast to the existing retrospective activity of medical audit. There is now considerable political pressure on the medical profession to rapidly develop procedures for measuring quality that will inevitably lead to the creation of local peer review. This will become a major challenge for Occupational Medicine because of substantial differences between this and other clinical specialities. He closed by explaining that the title made reference to the maintenance of the quality of 30 years of professional practice after completion of postgraduate training.

\section{A view from MOD Centre - Surg Cdre CW Evans.}

This presentation reviewed the major issues that had faced the Surgeon General over the recent past. There was discussion on immunisation policy, the Strategic Defence Review, the future of Royal Hospital Haslar, and the recruitment and retention of secondary care personnel.

Ethics and the Occupational Physician - Dr DS Wright.

Dr Wright is chairman of the Ethics Committee of the Faculty of Occupational Medicine. He started with a definition of medical ethics as 'a consensus within a recognised section of the medical profession on appropriate standards of behaviour by members of that group'. Thus 'ethics' belongs to all members of the profession and is not solely the domain of individual practitioners. The environment in which ethical issues are considered by the medical profession is subject to continual change. He identified the following areas of ethical concern to the Armed Forces: the balance between confidentiality and public interest, the relative youth and isolation of Service doctors, the Service disciplinary code and rank structure and the unique role of preventive medicine programmes to counter weapon threats. Occupational medicine is a unique clinical speciality which is affected by changes in health and safety 
legislation and employment law as well as issues relating to public expectations, self-regulation and changes in practice. Ethics remains a major challenge for occupational medicine.

\section{Entry Medicals - A Perspective. Surg Capt JJW Sykes.}

This paper reviewed the system of medical selection to the Royal Navy. The system starts with a basic medical enquiry at the Careers Office. After the non-medical entry standards have been met, the candidate is assessed by the Final Examining Medical Officer (FEMO). When candidates are called forward for training they receive a final medical examination at the training establishment. A review of the process for sailors in 1996 showed that medical discharges were an order of magnitude less than PVR and Discharged Unsuitable During Training. There were 65 discharges due to medical reasons: 6 FEMO errors, 6 conditions not declared, 8 conditions developed after FEMO examination, 2 cleared at Consultant level before entry, 27 declared previous history which had been deemed acceptable. A questionnaire survey was undertaken for the period Mar-Aug 97 to evaluate the efficiency of the screening process. There was an $82 \%$ response rate from Careers Offices. In summary approximately 6000 candidates are medically examined annually of which 600 are rejected. There is a $1 \%$ error rate for passing candidates fit. Most rejections are made on history or objective findings. Finally it was proposed that pre-employment screening could be conducted by occupational health nurses rather than doctors but that this requires further examination before implementation.

\section{Medical Aspects of Recruiting - Maj I Gemmell.}

The Army has the largest recruiting organisation in UK. Medical screening is conducted in 4 Recruit Selection Centres (RSCs) which employ 83 Civilian Medical Practitioners (CMPs). In 1997 there were 31000 enquiries which led to 27000 applicants (4000 lost on basis of medical declaration). 22000 candidates were called to the RSCs ( 2500 failed medical examinations) of which 17000 enlisted ( 300 failed to declare relevant medical conditions, FTD). Twenty five percent of applicants had a medical condition that rendered them below entry standards. Proposals to improve the system include: audit, reduction in the rate of FTD, improvement in the detection of conditions, and revision of JSP 346. The most prevalent pre-existing conditions causing rejection were: low back pain, asthma, old knee injury, Osgood Schlatter's disease, migraine, visual disturbance and epilepsy. The approximate cost of FTD was $£ 3000$ per recruit totalling $£ 900,000$ per year. Possible action for the future includes: the use of GP questionnaires, allowing more time for medical examinations, improving training for examining doctors, and reducing waiting times for referral for specialist opinion.

\section{PULHHEEMS - an audit - Lt Col MS Adams.}

The history of medical classification in the British Army was reviewed with an explanation of the evolution of the PULHHEEMS system. The system for medical classification in the British Army must reflect current arrangements for the delivery of healthcare. It should be noted that $56 \%$ Regular Army personnel have their primary care provided by civilian medical practioners (CMPs), $85 \%$ of Regular medical officers are singlehanded and the changes in provision of secondary care have resulted from the formation of the Defence Secondary Care Agency (DSCA). The paper presented an audit of the application of the PULHHEEMS system for Regular personnel. The results showed that $6.5 \%$ of soldiers were outside Fit Everywhere (FE) limits and $84.9 \%$ of referrals remained FE when $94 \%$ of this group should have been regraded. The current system relies on secondary care consultants to provide advice and administration for medical boards but the formation of the DSCA has reduced the capability of secondary care to provide this service.

\section{The Royal Hospital Haslar (RHH) Hyperbaric Medicine Unit - Surg Cdr PJ Benton.}

This paper reviewed the first two years results of this facility. The RHH Hyperbaric Unit is a venture jointly manned by personnel from INM, DERA Alverstoke and RHH. The paper outlined the clinical indications for hyperbaric therapy and its mode of action. The unit had treated 266 cases with 754 separate treatments. The unit treats decompression illness, carbon monoxide poisoning, problem wounds and has participated in a treatment trial of radiation induced brachialplexopathy. Finally the role of occupational medicine physicians in the developing speciality of hyperbaric medicine was acknowledged.

\section{Occupational health on a humanitarian operation - Col A Hawley.}

The importance of health and safety on a humanitarian operation in Rwanda - Operation Gabriel was discussed. An outline decision tool was presented which required sequential analysis of the hazard; exposure; risk assessment; risk management and health surveillance. Particular issues that arose from this operation included psychological stress, HIV, the management of needlestick incidents, the role of Field Surgical Teams and the scaling of medical equipment.

\section{Assessing The Hazards From The South-East Asia Smog - Lessons For Military Environmental Medicine - Maj MCM Bricknell.}

This paper reported the results of a visit to Brunei of an Army Environmental Health Advisory Team in April 1998. The team was sent to Brunei to assess the risks to the health of Ministry of Defence personnel and their dependants from the smoke arising from the extensive forest fires burning in Indonesia. This paper presented a model for the assessment of risk for MOD employees and their dependants from environmental pollutants. It was suggested that this type of risk assessment will become an increasingly important issue for military operations.

\section{Army Aviation Medicine - future prospects and challenges -} Col MA Braithwaite.

The mission and function of Army Aviation Medicine was reviewed. There was specific discussion on the aircrew spatial disorientation sortie to increase awareness of the fallibility of the special senses. Future issues include: audit of the selection of candidates and screening blood test results, ergonomics and lasers in the Apache helicopter, aircrew and passenger helmets, laser protection, visual correction, $\mathrm{NBC}$, underwater escape, simulation, $\mathrm{G}$ tolerance, and finally the establishment of a longterm cohort study in Apache aircrew.

\section{Aircraft accident investigation - Maj PA Cain.}

This paper reviewed the role of the specialist in aviation medicine in aircraft accident investigation. This was divided into the following issues: container (Is there sufficient space left in the crew space consistent with survival?), restraints (Have the restraints worked?), environment, energy absorption (including human damage) and post crash factors (fire etc).

\section{Eye Protection for Aircrew using the Laser Target Designator/Rangefinder - Lt Col A Eke.}

The effects of lasers on aircrew as dazzle, temporary blinding and permanent eye damage was summarised. The assessment process for laser safety from the manual on military laser safety, JSP 390, was reviewed. This process is: hazard evaluation - 
safety procedures - individual protection - medical surveillance. The presentation ended with an outline of concepts for the future.

Use of information systems in occupational medicine - Wg Cdr AC Wilcock.

This presentation discussed the relevance of information systems to support occupational medicine. There is a requirement for personnel data (personal identifiers, health status, sickness absence, and ill-health retirement), workplace data (hazards, risks and exposure) and data on occupational medicine outputs and costs. This must include a mechanism for integration of data and data storage. The Armed Forces have an advantage over other occupational medicine systems by providing a comprehensive health service for its uniformed employees. The basis for the occupational medicine component of health records could be found from $\mathrm{COSHH}$ regulations. The existing Armed Forces Primary Health Care Information System may provide an opportunity to develop such a system. The presentation reviewed a trial called Occupational Medical Data Set linked to EMIS. GPs were asked to link attendance with exposure to hazards at work. The results showed $23 \%$ of attendances were related to occupation, $12 \%$ for medical assessments and $15 \%$ for mental disorders classified as caused by occupation. The trial demonstrated a capability to create a centralised medical dataset that could be used to provide information to support policy, planning and research.

There were the following poster presentations: The Hazards of Military Parachuting - Major MCM Bricknell, The Effects of음 Arduous Physical Exercise on a Group of Haematological, Biological and Immunological Measurements in Blood - $\mathrm{HA} \overrightarrow{\bar{F}}$ Chander, PO Collinson, MD Simmons and D Lewis, and $\frac{\text { }}{0}$ Quality in Occupational Health - RAF Institute of Health. In $\frac{C}{0}$ addition IMN had series of posters on communication in RN $\overline{\frac{F}{5}}$ damage control, transfer of casualties with spinal injuries in HM $\bar{\varnothing}$ ships and submarines, survival in a disabled submarine and the effectiveness of electrolyte beverages on short-term dehydration.

The symposium was an unqualified success providing an $\overrightarrow{\vec{\omega}}$

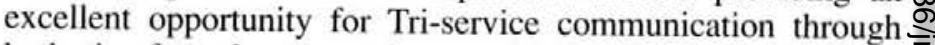
both the formal presentations and informal discussion. The papers proved the continued high academic quality of Service ? occupational medicine. It is hoped to make this symposium a $\overrightarrow{\vec{f}}$ regular event.

\title{
REPORT
}

\section{Symposium - Commemoration of the Liberation of the Bergen-Belsen Concentration Camp and Medical Management of Disasters Study Period}

\section{Lt Col RF Cordell \\ BSc,MB,BS,MRCGP,DCH,DRCOG,DipIMC,RCSEd,RAMC Commanding Officer}

1 Armd Fd Amb RAMC, Glyn Hughes Barracks, BFPO 30

\author{
Dr DH Forsdick \\ MB,BS \\ Retired General Practitioner
}

Winchester, Hants

SUMMARY: Over the period 15/16 April 1998 a commemorative dinner and study period was held to recognise the role of the medical services in the management of the victims of the Bergen-Belsen Concentration Camp. Having been presented with a framework for planning medical support to these situations, one of the London medical students at Belsen in 1945 related his own experience at this unprecedented and horrific scene. Following this, the lessons that may be drawn were examined, the key factor being the need to create order out of chaos. The system used by the military for analysing what has to be achieved in a given situation, and the deductions that can be made from the prevailing factors, called the Estimate Process, emerged as a model for planning the medical contribution to disaster relief.

\section{Introduction}

The Centenary of the Royal Army Medical Corps was marked by 1 Armoured Field Ambulance with a commemorative dinner and study period on 15/16 April 1998. This event recognised the contribution of medical personnel to the liberation of the nearby Bergen-Belsen Concentration Camp 53 years previously, and examined the lessons that can be drawn from the experience of this and other disasters. The key individual, who directed the medical relief effort, was Brigadier Glyn Hughes CBE DSO and two bars MC, after whom our barracks in Hohne Camp, North Germany, is named.

Following the fortieth anniversary of the Second World War, articles were published in this journal $(1,2)$ relating the part played by members of the RAMC in the liberation of Belsen in April 1945. These reflect the efforts of 32 Casualty Clearing Station, under the command of Lt Col JAD Johnston MC, and

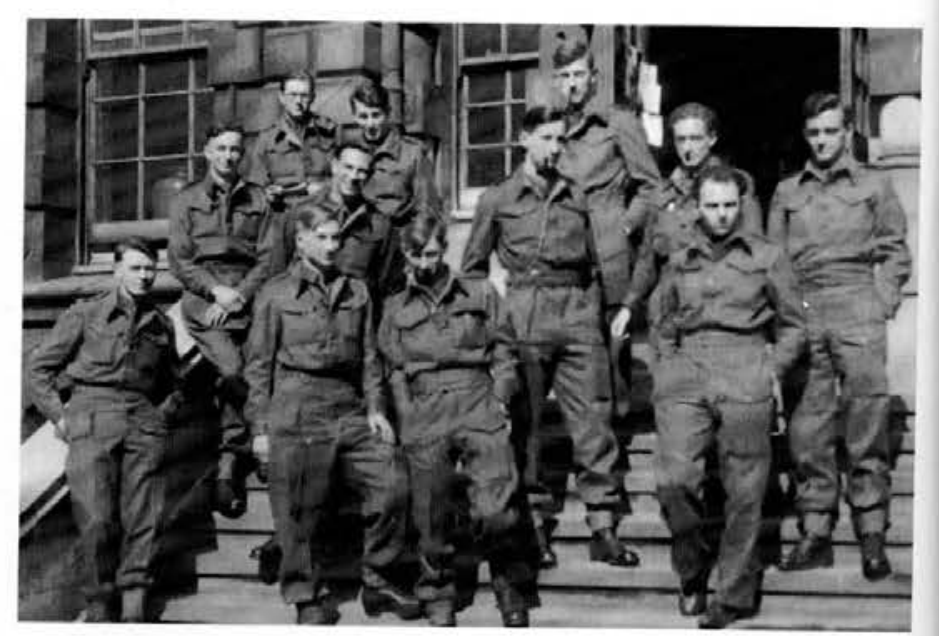

